\section{Mutation Screening of the Factor VIII Gene in Hemophilia A in Saudi Arabia: Two Novel Mutations and Genotype-Phenotype Correlation}

Faisal A Al-Allaf ${ }^{1,2,3 \#}$, Mohiuddin M Taher ${ }^{3 \# *}$, Zainularifeen Abduljaleel ${ }^{3}$, Mohammad Athar ${ }^{3}$, Faisal A Ba-hammam ${ }^{3}$, Munir Abdulla $^{3}$, Abdellatif $^{2}$ Bouazzaoui $^{3}$, Halah Abalkhail ${ }^{4}$ and Tarek MA Owaidah ${ }^{4 *}$

${ }^{1}$ Faculty of Medicine, Department of Medical Genetics, Umm Al-Qura University, Makkah, Saudi Arabia

${ }^{2}$ Molecular Diagnostics Unit, Department of Laboratory Medicine and Blood Bank, King Abdullah Medical City, Makkah, Saudi Arabia

${ }^{3}$ Science and Technology Unit, Umm Al-Qura University, Makkah, Saudi Arabia

${ }^{4}$ Pathology and Laboratory Medicine, King Faisal Specialist Hospital and Research Centre, Riyadh, Saudi Arabia

\#Equal first authors

\begin{abstract}
Background: Hemophilia A is an X-linked bleeding disorder caused by mutations in the factor VIII gene (F8C). Molecular testing for the factor VIII gene is difficult due to its large size. More than 1000 different mutations have been described in factor VIII gene. In this study we have investigated the factor VIII gene mutations in Saudi Arabian population.

Methods: For genotyping factor VIII cohorts of 110 samples from Saudi Arabian patients undergoing treatment for hemophilia A were collected. All patients were tested for factor VIII coagulant activity on Behring Coagulation System. Genomic DNA was isolated from blood on MagNapure system. Screening for inv-1 was done by multiplex PCR method, and inv-22 was done by ligation (inverse) PCR method. DNA sequencing was performed by Sanger method for all 26 exons of factor VIII gene. PCR products were sequenced on ABI 3500 Genetic analyzer. For molecular simulations we have used softwares such as CHARMM and GROMACS v4.0.527. In order to predict the possible impact of a variation on the function of factor VIII gene the online tools Polyphen 2, and SIFT were used.
\end{abstract}

Results: Out of 110 cases screened, 2 patients were positive (affected) for inv- 1 and 15 patients were positive (12 affected and 3 carriers) for inv-22. Out of 32 cases sequenced for coding exons, 2 novel mutations were found one novel missense mutation c.355G $>C$, p. (A119P) in exon 3 , and another novel frame shift mutation c.6482delC, p.(P2161 Lfs $\left.{ }^{\star} 25\right)$ in exon 23. Also known mutations such as, c.409 A>C, p. (T137P) in 2 individual patients in exon 4, another known mutation c. $1804 \mathrm{C}>\mathrm{T}, \mathrm{p} .\left(\mathrm{R} 602^{*}\right)$ in 1 patient in exon 12 were found. Genotype-phenotype correlations and computer prediction analysis on these novel mutations and the secondary structure analysis of the factor VIII protein were performed, and compared with the predicted native proteins.

Conclusions: These novel mutations in factor VIII gene and molecular dynamic simulation results to appropriately predict the deleterious effects of these mutations are presented in this study. In addition, for the native and mutant proteins models, the amino acid residues and its secondary structures were determined. Our $I n$-silico study suggests that these mutations have significant impact on the structure and function of the factor VIII protein.

Keywords: Hemophilia A; F8 Protein; Saudi Arabia; Blood coagulation; Computer simulation

\section{Introduction}

Hemophilia is classified into three types, according to the deficiencies in clotting factors. Hemophilia A (OMIM 306700) occurs when clotting factor VIII is either absent or not present in sufficient amounts $[1,2]$. Since this is the most common type, it is frequently referred to as classic hemophilia. Hemophilia A is hereditary X-linked recessive, where heterozygous females transmit the affected gene and the disease phenotype presents almost exclusively in males $[3,4]$. However, several women, those carrying the disease, might have mild symptoms of this disease [5]. Hemophilia B (also called Christmas disease) occurs when clotting factor IX is either absent or not present in sufficient amounts [6-8]. Hemophilia A affects 1 in 5000 males, and hemophilia B affects 1 in 30,000 males $[9,10]$. Hemophilia C (also known as Rosenthal syndrome) occurs when clotting factor XI is either absent or not present in sufficient amounts, it is extremely rare, it is reported to occur in Ashkenazi Jewish population, and it affects 1 in 100,000 adults in USA [11,12]. Hemophilia A and hemophilia B are the most common, over 80 percent of patients have hemophilia A (classical hemophilia), and hemophilia B affects about 15 per cent of hemophiliacs. However, in the Arab world the most common type of hemophilia is yet to be determined [13]. Other coagulation factor deficiencies are less common, with patients suffering either milder bleeding or thrombotic episodes.

The human factor VIII gene was cloned between 1982 and 1984 [14]. Factor VIII is synthesized in the liver, and it circulates in the plasma in a stable complex with von Willebrand factor (vWF), that inhibits the proteolytic degradation of factor VIII. Factor VIII activation occurs on the surface of platelets, and is initiated by thrombin or factor Xa. Activated factor VIII (factor VIIIa) is a cofactor for factor

*Corresponding authors: Mohiuddin M Taher, Science and Technology Unit Umm Al-Qura University, Makkah, Saudi Arabia, Tel: 966125501000; E-mail: taher23223@yahoo.com

Tarek M A Owaidah, Pathology and Laboratory Medicine, King Faisal Specialist Hospital and Research Centre, Riyadh, Saudi Arabia, Tel: 966114647272; E-mail: towaidah@kfshrc.edu.sa

Received November 18, 2015; Accepted April 26, 2016; Published April 31, 2016

Citation: Al-Allaf FA, Taher MM, Abduljaleel Z, Athar M, Ba-hammam FA, et al. (2016) Mutation Screening of the Factor VIII Gene in Hemophilia A in Saudi Arabia: Two Novel Mutations and Genotype-Phenotype Correlation. J Mol Genet Med 10: 211 doi:10.4172/1747-0862.1000211

Copyright: (c) 2016 Al-AllaF FA, et al. This is an open-access article distributed under the terms of the Creative Commons Attribution License, which permits unrestricted use, distribution, and reproduction in any medium, provided the original author and source are credited 
IXa activation and enhances the reaction approximately 10,000 fold. Genetic mutations in factor VIII cause deregulation of this protein leading to bleeding disorders [15-19]. Defects in factor VIII gene includes deletions, large DNA inversions, nonsense mutations, ins/ del-frame shifts, splice variants and a large number of missense point mutations, all of which can cause defects in the expression, secretion, and/or half-life of factor VIII protein in circulation [20-25]. According to western reports around $1-5 \%$ of hemophilia A cases known to have intron-1 inversion in factor VIII gene [19,24], and the intron-22 inversion is the most common mutation in hemophilia A responsible for about $40-50 \%$ of severe cases [26].

One third of hemophilia A cases are sporadic with no prior family history of the disease [27,28]. Several studies are available in literature describing the mutations in factor VIII gene, from many ethnic groups and different populations $[16,17,25,29,30]$. Recently, some reports were published from Middle Eastern countries also describing factor VIII gene mutations [31-34]. However, the spectrum and nature of common mutations causing hemophilia A in Arab population specifically in Saudi Arabs is not clear. Therefore, we plan to study the mutations in factor VIII gene from Saudi Arabian hemophilia A patients that could help in screening and treating this genetic disorder. These tests will offer a fast and reliable mutation screening method that can also be applied in the future for prenatal genetic diagnosis to families at risk of having a child with hemophilia.

\section{Materials and Methods}

\section{Samples collection and storage}

For factor VIII investigation a cohort of 110 samples undergoing treatment at King Faisal Specialist Hospital and Research Centre, Riyadh (KFSH\&RC) were collected. Out 110 cases, $75 \%$ were severe hemophilia A, $17 \%$ cases were mild, and $8 \%$ cases were moderate hemophilia A. Severity was determined as described by world federation of hemophilia (http://www.wfh.org). Representative hemophilia A patient's clinical characteristics and symptoms are shown in Table-3. All patients were tested for factor VIII coagulant activities that were carried out on Behring Coagulation System (BCS; Siemens, Marburg $\mathrm{GmbH}$, Germany) using chromogenic assay. Ethical approvals were obtained from the participated institutions. Detailed medical history of individuals and families was taken to confirm the pattern of inheritance. British Committee for Standards in Haematology Guidelines (bcshguidelines.org) were followed for the patient's selection criteria. Genomic DNA was isolated from EDTA whole blood with the MagNA Pure compact nucleic acid isolation Kit-I.

\section{Factor VIII intron 1 and 22 inversion assays}

Intron-1 inversion (inv-1) was done by the method of Bagnall et al. PCR amplification was done using Fermentas kit. The primers used in PCR - A were 9FW, 9 CRV, and int-1h 2FW; and in PCR -B were, 9FW, int-1h $2 \mathrm{FW}$ and int-1h-2 RV shown in Table 1. Factor VIII intron-22 inversion (inv-22) was done by inverse PCR method $(35,36)$, replacing the long PCR assays, as it is more robust than the long-PCR [35] Inverse-PCR (I-PCR) involves 3 steps:

(1). Bcl1 restriction digestion.

(2). Self-ligation of restriction fragments, two relevant B-rings (self-ligated BclI fragments) are formed after BclI digestion and ligation, in normal case a $21.5-\mathrm{kb}$ ring that corresponds to the non-rearranged copy of int-22h-1 (Normal B-ring); and inv-22 containing B-ring, a $20-\mathrm{kb}$ ring that spans a chimeric copy of int-
$22 h$ composed by a part of int-22h-1 (intragenic) and part of either int-22h-2 (proximal) or int-22h-3 (distal). Each ring is specifically recognized by a specific PCR amplification. Normal B-rings yield product of $487 \mathrm{bp}$ with primers IU and ID; Inv-22 positive B-ring yield products of $559 \mathrm{bp}$ with primers IU and ED.

(3). Standard multiplex PCR analysis. PCR is achieved by using 3 primers as shown in Table 2. A minimum of $500 \mathrm{ng}$ to $1.0 \mu \mathrm{g}$ of DNA was used in this assay [36,37].

\section{DNA sequencing by capillary method}

Polymerase chain reaction (PCR) products were sequenced for all 26 exons of factor VIII by Sanger method and analyzed on ABI 3500 Genetic analyzer as described by [17,33]. Descriptions of the primers used for amplification and sequencing were reported previously $[38,39]$. PCR was performed with $100 \mathrm{ng}$ of genomic DNA using a HotStarTaq Plus DNA polymerase (Qiagen) in $20 \mu \mathrm{ls}$ volume. PCR cycling conditions were 40 cycles with denaturation at $95^{\circ} \mathrm{C}$ for $30 \mathrm{sec}$; annealing at $60^{\circ} \mathrm{C}$ for $30 \mathrm{sec}$; and extension at $68^{\circ} \mathrm{C}$ for 1 minute. The PCR products were purified by magnetic beads method using Agencourt AMPure XP kit and used in Big Dye Terminator v3.1 cycle sequencing reaction. The Big Dye reaction products were purified with Big Dye $\mathrm{X}$-terminator purification kit, followed by capillary electrophoresis, and the sequences were verified on Applied Biosystem's Sequence Analysis software v5.4 for quality, and the final mutation analysis was performed on CLC genomics workbench. Mutations were designated according to the Human Genome Variation Society guidelines [40]. In order to predict the possible impact of a variation on the function of factor VIII gene the online tools Polyphen 2 (http://genetics.bwh. harvard.edu/pph2/); and SIFT (http://sift.jcvi.org/www/SIFT_enst_ submit.html) were used.

\section{Molecular dynamics (MD) simulation}

For molecular simulations and genotype phenotype correlations we have used the softwares such as CHARMM (Chemistry at Harvard Macromolecular Mechanics; http://www.charmm-gui.org) and GROMACS v4.0.527. The molecular dynamics (MD) simulations were

\begin{tabular}{|c|c|}
\hline PCR-A & Sequence \\
\hline 9fw (20 mer) & 5' - GTTGTTGGGAATGGTTACGG - 3' \\
\hline 9crv (20 mer) & 5' - CTAGCTTGAGCTCCCTGTGG $-3{ }^{\prime}$ \\
\hline Int-1h 2fw (21 mer) & 5' - GGCAGGGATCTTGTTGGTAAA - 3' \\
\hline PCR-B & \\
\hline 9fw (20 mer) & 5' - GTTGTTGGGAATGGTTACGG - 3' \\
\hline Int-1 $h$ 2fw (21 mer) & 5' - GGCAGGGATCTTGTTGGTAAA - 3' \\
\hline Int-1h 2rv (24 mer) & 5' - TGGGTGATATAAGCTGCTGAGCTA - 3' \\
\hline
\end{tabular}

Table 1: Primers used for inv-I testing by PCR method [24].

\begin{tabular}{|c|c|c|c|}
\hline Primer & Sequence & NC_000023.9 & Bc/l site* \\
\hline IU (20 mer) & $\begin{array}{c}5^{\prime} \text { - CCT TTC AAC TCC ATC TCC } \\
\text { AT - 3' }\end{array}$ & $\begin{array}{l}153779730- \\
50\end{array}$ & 460 \\
\hline ID (21 mer) & $\begin{array}{c}5^{\prime} \text { - ACA TAC GGT TTA GTC ACA } \\
\text { AGT - 3' }\end{array}$ & $\begin{array}{l}153758587- \\
608\end{array}$ & 27 \\
\hline \multirow{2}{*}{ ED (19 mer) } & \multirow{2}{*}{$\begin{array}{c}5^{\prime}-\text { TCC AGT CAC TTA GGC TCA } \\
\text { G - 3, }\end{array}$} & $\begin{array}{c}154257328- \\
47\end{array}$ & \multirow{2}{*}{99} \\
\hline & & $\begin{array}{l}154349067- \\
86\end{array}$ & \\
\hline
\end{tabular}

*DNA distance (bp) from the 5' end of the primer to the Bc/l restriction site. This DNA distance indicates the contribution of this primer usage to the inverse PCR product.

Table 2: Primers used for inv-22 testing by inverse PCR method [21] 
Citation: Al-Allaf FA, Taher MM, Abduljaleel Z, Athar M, Ba-hammam FA, et al. (2016) Mutation Screening of the Factor VIII Gene in Hemophilia A in Saudi Arabia: Two Novel Mutations and Genotype-Phenotype Correlation. J Mol Genet Med 10: 211 doi:10.4172/1747-0862.1000211

Page 3 of 11

performed with a 5 fs time step using set temperature of $300 \mathrm{~K}$ and constant pressure of $1 \mathrm{~atm}$, below periodic solvent boundary conditions. The knowledge based minimization (KoBaMIN) program [41], allowed refining the factor VIII domain A1 structure to evaluate changes as a result of refined protocol. The conjugate gradient technique for $3 \mathrm{D}$ structure optimization along with the deviation between the structures was assessed by their RMSD values. This server utilizes GROMACS for force field energy minimization conjugate gradient and Limited reminiscence Broyden Fletcher Goldfarb Shanno (L-BFGS) methods [42]. The free energy simulations were performed with solvent water molecules in close proximity to the solute to get an efficient solvent boundary potential (SSBP). The configuration of ions was first verified by brief Monte Carlo (MC) simulation based on Van Der Waals (VdW) interactions. The Particle Mesh Ewald [43] methodology was utilized for electrostatics observations and a $12 \AA$ cutoff was applied for VdW interactions. The mutations were further studied utilizing (Collaborative Computational Project, number 4) CCP4; QtMG and energy minimization for 3D structures were carried out using NOMAD-Ref server. Molecular Operation Environment (MOE) was used to assess the associated hemophilia-A disease variants in the factor VIII protein. Furthermore, SWISS-PROT and CCP4 (QTMG) analyzed the structure conformational changes of factor VIII protein domains.

The protein stability was determined by Schrodinger (BioLuminate) increased insights. Structure analysis was performed using Have Your Protein Defined (HOPE) [44], developed by the Centre for Molecular and Bio-molecular Informatics (CMBI), department of Bioinformatics, Radboud University. This program was used to observe the impact of mutation variant on the factor VIII protein domain A1. The analysis was based on the parameters of functional contacts like metal, DNA, hydrogen bonds, ionic interactions, and structural areas together with motifs, domains and transmembrane domains. The last three parameters are very important to acquire factual data of actual protein structure resulting in annotated information in UniProtKB DAS servers [45]. Initially, we checked whether the mutation was located in the factor VIII protein based on assigned and corresponding function, non-structural features like posttranslational modifications based on a protein sequence in FASTA format. Additionally, we have also compared the predictions of the functional effects that were determined by the SNAP $[46,47]$.

\section{Results}

\section{Analysis of samples for Inversion 1 in Factor VIII gene}

Representative hemophilia A patient's clinical characteristics and symptoms are shown in Table 3 . All of the 110 samples were analyzed for the inv -1 in factor VIII gene, two male patients were positive (affected) for inv-1 and all other patients were wild type (Table 4). Representative PCR gel pictures are shown in Figures 1A and 1B. In Figure 1, PCR bands for wild type alleles (1.9 kb in PCR-A; and $1.2 \mathrm{~kb}$ in PCR-B) in panel A; and affected with hemophilia (1.3 kb in PCR-A; and $1.8 \mathrm{~kb}$ in PCR-B) in panel B are indicated by arrows. One 25 years old male patient with chronic joint disability in left knee (code no. Inv11) had mild hemophilia A with factor VIII base line levels of 5-40\%. In Figure 1 panel B the PCR products of a patient affected with hemophilia A were shown, this patient is a 18 years old male patient with chronic joint disability in right knee (code no. Inv-1-2) and he had severe form of hemophilia with factor VIII base line levels of $<1 \%$ (Table 3 ). Factor VIII inhibitor was absent in both of these patients.

\section{Analysis of samples for Inversion 22 in Factor VIII gene}

A total of 108 patients (after removing the two inv-1 positives) with hemophilia A, were analyzed for the inv-22 in factor VIII gene. 15 cases out of 75 severe cases (20\%) were positive for inv-22 in the factor VIII gene and all other patients were wild type for inv-22. Out of these 15 positive cases, 3 were carriers (female), and 12 were affected (male) with hemophilia A (Table 4). All these patients have elevated pro-thrombin time (PTT) with severe form of hemophilia with factor VIII base line levels of $<1 \%$ (Table 3). The inv-22 PCR gels are shown in Figure 2A and $2 \mathrm{~B}$ for a representative of samples. The clinical characteristics' of representative patients and the summary of positive samples are shown in Tables 3 and 4 .
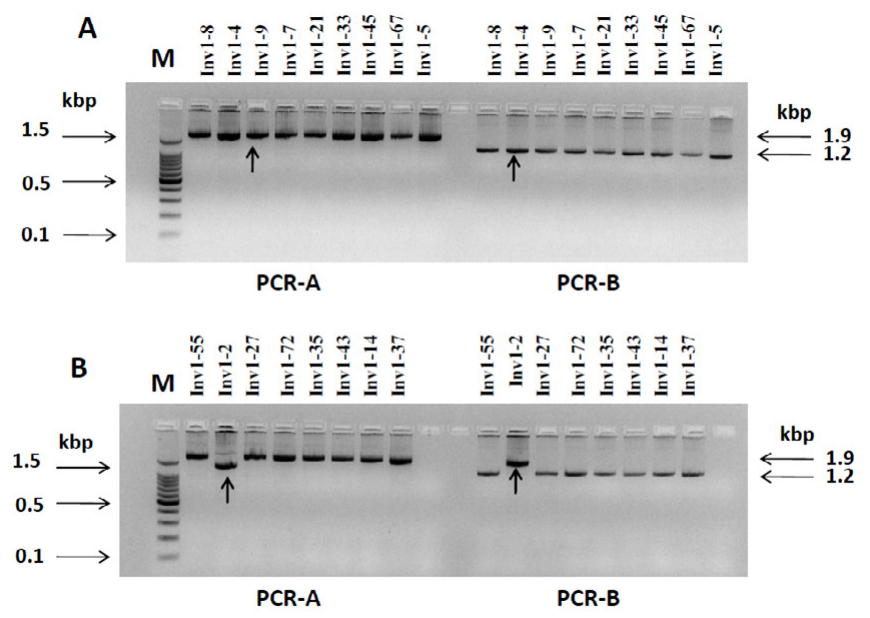

Figure 1: Inversion-1 assay for Factor VIII intron-1. Representative Gel Picture showing patients samples with wild type alleles in Panel $A$ and $B$ arrows indicating $1.9 \mathrm{~kb}$ in PCR-A; and $1.2 \mathrm{~kb}$ in PCR-B; and haemophilic allele (affected) with products (arrow $1.3 \mathrm{~kb}$ in PCR-A; and arrow $1.8 \mathrm{~kb}$ in PCR-B) in Panel B. Lane M indicates 100 bp ladder.

A

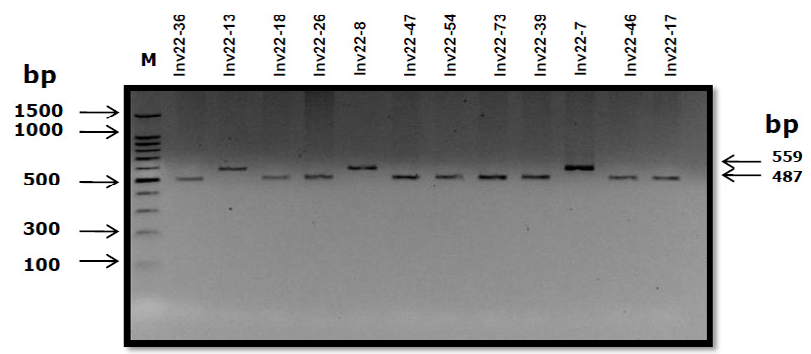

B

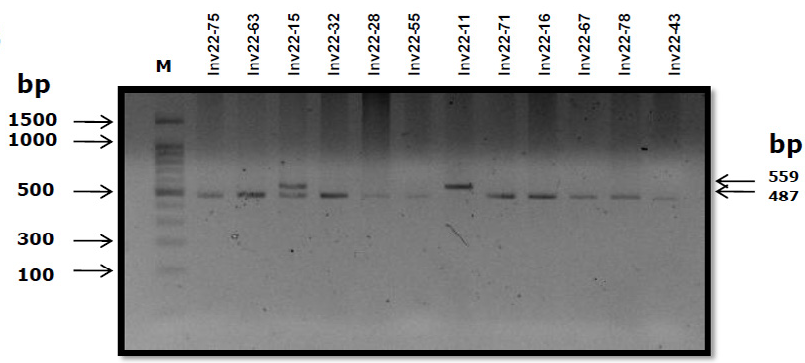

Figure 2: Inversion PCR assay for Factor VIII intron-22 inversion. Panel (A) Representative Gel Picture showing inv-22 PCR gel bands for normal allele (487 bp) and hemophilic (affected) allele (559 bp). Panel (B) Representative gel showing bands for normal allele (487 bp); affected allele (559bp) and hemophilic carrier allele (487 and 559 bps). Lanes 1 - 12 are patient's samples; letter 'M' indicates $100 \mathrm{bp}$ ladder. 
Citation: Al-Allaf FA, Taher MM, Abduljaleel Z, Athar M, Ba-hammam FA, et al. (2016) Mutation Screening of the Factor VIII Gene in Hemophilia A in Saudi Arabia: Two Novel Mutations and Genotype-Phenotype Correlation. J Mol Genet Med 10: 211 doi:10.4172/1747-0862.1000211

Page 4 of 11

\begin{tabular}{|c|c|c|c|c|c|c|c|}
\hline Code No. & Gender & Age (Yrs) & Severity & Type of Care & Treatment Products Used & $\begin{array}{l}\text { Presence of Joint } \\
\text { Disability }\end{array}$ & PTT \\
\hline Inv-22-1 & Male & 18 & Severe $(<1 \%)$ & Episodic & Plasma Derived Clotting Factor & Right Elbow & 112 \\
\hline Inv-1-1 & Male & 25 & Mild (5 to $40 \%)$ & Prophylaxis & Plasma Derived Clotting Factor & Left Knee & NA \\
\hline UQU-HA9 & Male & 6 & Moderate $(1$ to $<5 \%$ ) & Episodic & Plasma Derived Clotting Factor & No & NA \\
\hline Inv-22-2 & Male & 25 & Severe $(<1 \%)$ & Episodic & Fresh Frozen Plasma & Right Elbow & 85.9 \\
\hline Inv-22-3 & Male & 32 & Severe $(<1 \%)$ & Prophylaxis & Fresh Frozen Plasma & Right Knee Left Ankle & 58.7 \\
\hline Inv-22-4 & Male & 26 & Severe $(<1 \%)$ & Episodic & Fresh Frozen Plasma & Right Knee & 68.3 \\
\hline Inv-1-2 & Male & 19 & Severe $(<1 \%)$ & Episodic & Plasma Derived Clotting Factor & Right Knee & 101 \\
\hline Inv-22-5 & Male & 17 & Severe $(<1 \%)$ & Prophylaxis & Fresh Frozen Plasma & Right Ankle and Elbow & 85.6 \\
\hline UQU-HA6 & Male & 51 & Severe $(<1 \%)$ & Episodic & Plasma Derived Clotting Factor & $\begin{array}{l}\text { Right Knee, Left Elbow, } \\
\text { Left Ankle }\end{array}$ & 125.4 \\
\hline Inv-22-6 & Male & 28 & Severe $(<1 \%)$ & Prophylaxis & Plasma Derived Clotting Factor & Right Elbow & 141.6 \\
\hline Inv-22-7 & Male & 32 & Severe $(<1 \%)$ & Prophylaxis & Plasma Derived Clotting Factor & Unknown & 84 \\
\hline Inv-22-8 & Male & 15 & Severe $(<1 \%)$ & Episodic & Plasma Derived Clotting Factor & Unknown & 127.8 \\
\hline Inv-22-9 & Male & 9 & Severe $(<1 \%)$ & Episodic & Plasma Derived Clotting Factor & Unknown & 46.4 \\
\hline UQU-HA7 & Male & 11 & Severe $(<1 \%)$ & Episodic & Fresh Frozen Plasma & No & 150 \\
\hline
\end{tabular}

Table 3: Summary table showing representative Hemophilia A patient's clinical characteristics.

\begin{tabular}{|c|c|c|c|c|c|c|c|c|}
\hline Patient Code & Gender & Clinical Severity & \multicolumn{2}{|c|}{ Mutation Type/Effect } & Function & Exon/Intronic & Nucleotide/AA Changed & Novel \\
\hline UQU-HA4 & Male & Severe $(<1 \%)$ & Point & Missense & Delterious & Exon4 & c.409A>C, p.(T137P) & No \\
\hline UQU-HA6 & Male & Severe $(<1 \%)$ & Point & Missense & Delterious & Exon4 & c.409A>C, p. $(\mathrm{T} 137 \mathrm{P})$ & No \\
\hline UQU-HA7 & Male & Severe $(<1 \%)$ & Point & Missense & Delterious & Exon3 & c.355G>C, p. $(\mathrm{A} 119 \mathrm{P})$ & Yes \\
\hline UQU-HA14 & Male & Severe $(<1 \%)$ & Point & Termination & Delterious & Exon12 & c. $1804 \mathrm{C}>\mathrm{T}, \mathrm{p} .\left(\mathrm{R} 602^{*}\right)$ & No \\
\hline UQU-HA15 & Male & Severe $(<1 \%)$ & Frame Shift & Termination & Delterious & Exon23 & c.6482delC, p.(P2161Lfs*25) & Yes \\
\hline Inv-1-1 & Male & Mild (5 to $40 \%$ ) & \multicolumn{2}{|c|}{ Inv-1 } & Affected & IVS-1 & N/A & No \\
\hline Inv-1-2 & Male & Severe $(<1 \%)$ & \multicolumn{2}{|c|}{ Inv-1 } & Affected & IVS-1 & N/A & No \\
\hline Inv-22-1 & Male & Severe $(<1 \%)$ & \multicolumn{2}{|c|}{ Inv-22 } & Affected & IVS-22 & N/A & No \\
\hline Inv-22-2 & Male & Severe $(<1 \%)$ & \multicolumn{2}{|c|}{ Inv-22 } & Affected & IVS-22 & $\mathrm{N} / \mathrm{A}$ & No \\
\hline Inv-22-3 & Male & Severe $(<1 \%)$ & \multicolumn{2}{|c|}{ Inv-22 } & Affected & IVS-22 & $\mathrm{N} / \mathrm{A}$ & No \\
\hline Inv-22-4 & Male & Severe $(<1 \%)$ & \multicolumn{2}{|c|}{ Inv-22 } & Affected & IVS-22 & $\mathrm{N} / \mathrm{A}$ & No \\
\hline Inv-22-5 & Male & Severe $(<1 \%)$ & \multicolumn{2}{|c|}{ Inv-22 } & Affected & IVS-22 & $\mathrm{N} / \mathrm{A}$ & No \\
\hline Inv-22-6 & Male & Severe $(<1 \%)$ & \multicolumn{2}{|c|}{ Inv-22 } & Affected & IVS-22 & N/A & No \\
\hline Inv-22-7 & Male & Severe $(<1 \%)$ & \multicolumn{2}{|c|}{ Inv-22 } & Affected & IVS-22 & N/A & No \\
\hline Inv-22-8 & Male & Severe $(<1 \%)$ & \multicolumn{2}{|c|}{ Inv-22 } & Affected & IVS-22 & N/A & No \\
\hline Inv-22-9 & Male & Severe $(<1 \%)$ & \multicolumn{2}{|c|}{ Inv-22 } & Affected & IVS-22 & N/A & No \\
\hline Inv-22-10 & Male & Severe $(<1 \%)$ & \multicolumn{2}{|c|}{ Inv-22 } & Affected & IVS-22 & N/A & No \\
\hline Inv-22-11 & Male & Severe $(<1 \%)$ & \multicolumn{2}{|c|}{ Inv-22 } & Affected & IVS-22 & N/A & No \\
\hline Inv-22-12 & Female & Severe $(<1 \%)$ & \multicolumn{2}{|c|}{ Inv-22 } & Carrier & IVS-22 & N/A & No \\
\hline Inv-22-13 & Male & Severe $(<1 \%)$ & \multicolumn{2}{|c|}{ Inv-22 } & Affected & IVS-22 & N/A & No \\
\hline Inv-22-14 & Female & Severe $(<1 \%)$ & \multicolumn{2}{|c|}{ Inv-22 } & Carrier & IVS-22 & N/A & No \\
\hline Inv-22-15 & Female & Severe $(<1 \%)$ & \multicolumn{2}{|c|}{ Inv-22 } & Carrier & IVS-22 & $\mathrm{N} / \mathrm{A}$ & No \\
\hline
\end{tabular}

Table 4: Summary of mutations detected in Saudi Arabian Hemophilia A patients.

\section{Analysis of mutations in Factor VIII gene by capillary} sequencing

32 samples of Saudi Arabian patients were sequenced for factor VIII gene. Out of 32 DNA samples screened, two novel mutations were found, one missense mutation in exon 3, [c.355G>C, p. (A119P)] another was a frame shift mutation in exon 23 [c.6482delC, p.(P2161Lfs $\left.\left.{ }^{\star} 25\right)\right]$. Also, two known mutations were found, in exon 4, c.409 A>C, p. (T137P) in 2 individual patients, another known mutation in exon 12, c.1804C $>\mathrm{T}$, p.(R602X) in 1 patient were found (Table 4). The patient with the novel mutation in exon 3 , was a 11 years, male, and had no joint pains with base line factor VIII levels of $<1 \%$ (severe form of hemophilia A) with episodic bleeding (Tables 3 and 4). This patient did not have any systemic manifestations. This patient was on more than one types of treatment plan with PTT 150 seconds (Table 3). This patient also tested positive for factor VIII inhibitor. This G>T mutation occurred in codon TGG of tryptophane to change in to TGT (cysteine) and this is present in A1 domain of factor VIII. This mutation of hydrophobic neutral alanine (GCT) to CCT codes to hydrophobic neutral aminoacid proline. In Figure 3, the electrophoregram is shown in panel $\mathrm{A}$, is for the wild type control, and in panel $\mathrm{B}$, for the patient with mutation in exon 3. In panel C, PCR gel picture is shown for exon 3 product size of $616 \mathrm{bp}$, the acutal exon 3 size is $123 \mathrm{bp}$.

Another novel mutation was identified in one male patient (18 yrs old), this is a frameshift mutation c.6482delC, p.(P2161Lfs $\left.{ }^{\star} 25\right)$ in exon 23 causing blood coagulation factor VIII deficiency. This delection of $\mathrm{C}$ in CCT codon of proline makes a frameshift to CTC (Leucine) and coding changes in further 24 (frameshift) makes a stop codon (TGA), at $25^{\text {th }}$ amino acid leading to transcriptional termination and truncated protein. In Figure 4, the electrophoregram is shown in panel A, is for the wild type control, and in panel $\mathrm{B}$, for the patient with mutation in exon 23. In panel C, PCR gel picture is shown for exon 23 product size of $416 \mathrm{bp}$, the acutal exon 23 size is $145 \mathrm{bp}$. This mutation is associated with severe form of haemophillia. The base line factor VIII levels were 


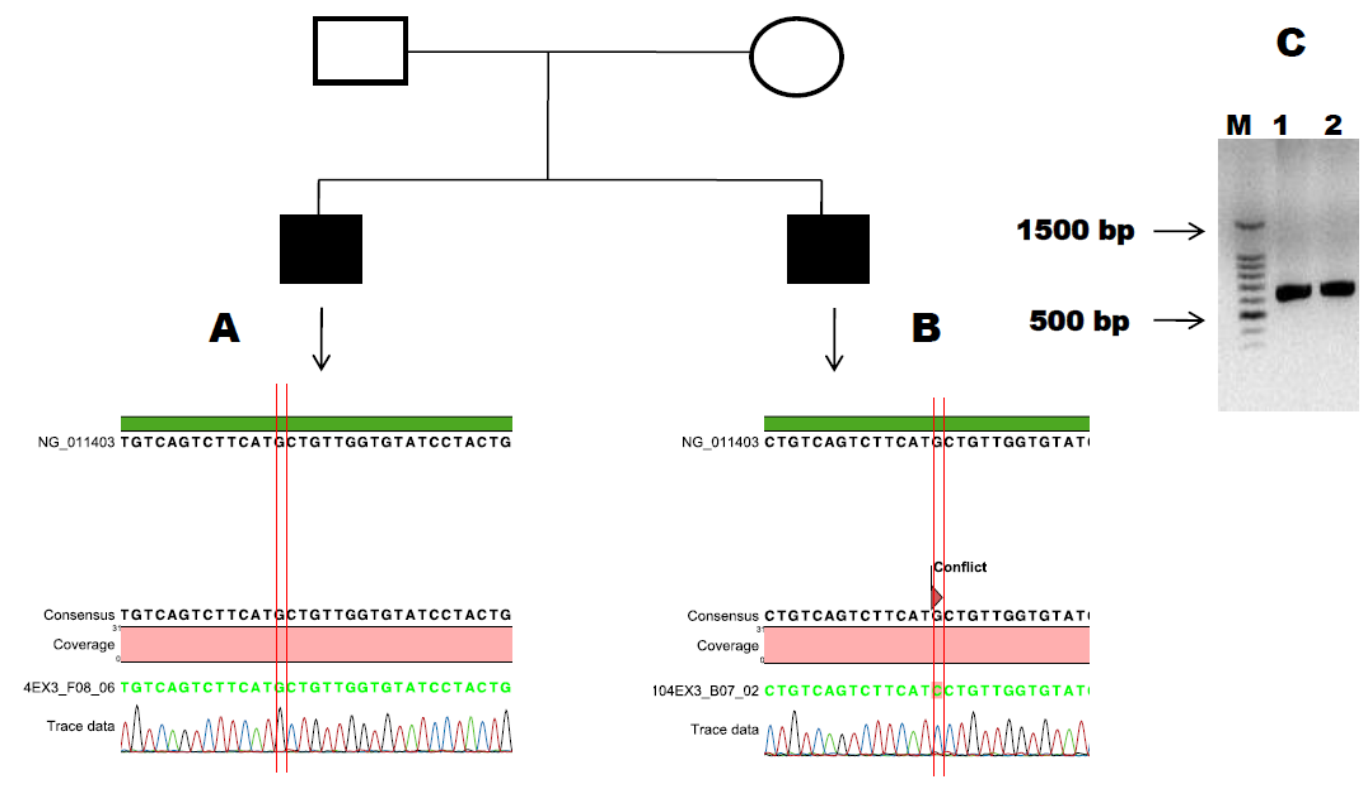

Figure 3: Identification of a novel missense mutation in coagulation factor VIII c.355G>C, p. (A119P) in Saudi Arabian patients. Family pedigree, open square and open circle represents parents (father and mother respectively), filled squares represents male family member. (A) Representative Electrophoregram showing WT genotype. (B) Representative Electrophoregram showing the mutation (conflict) in exon 3 of Factor VIII gene. (C) PCR gel image of exon 3 of Factor VIII showing single specific band of product size, 616 bp in patient and WT (Lanes - 1, 2). M represents 100 bp ladder.

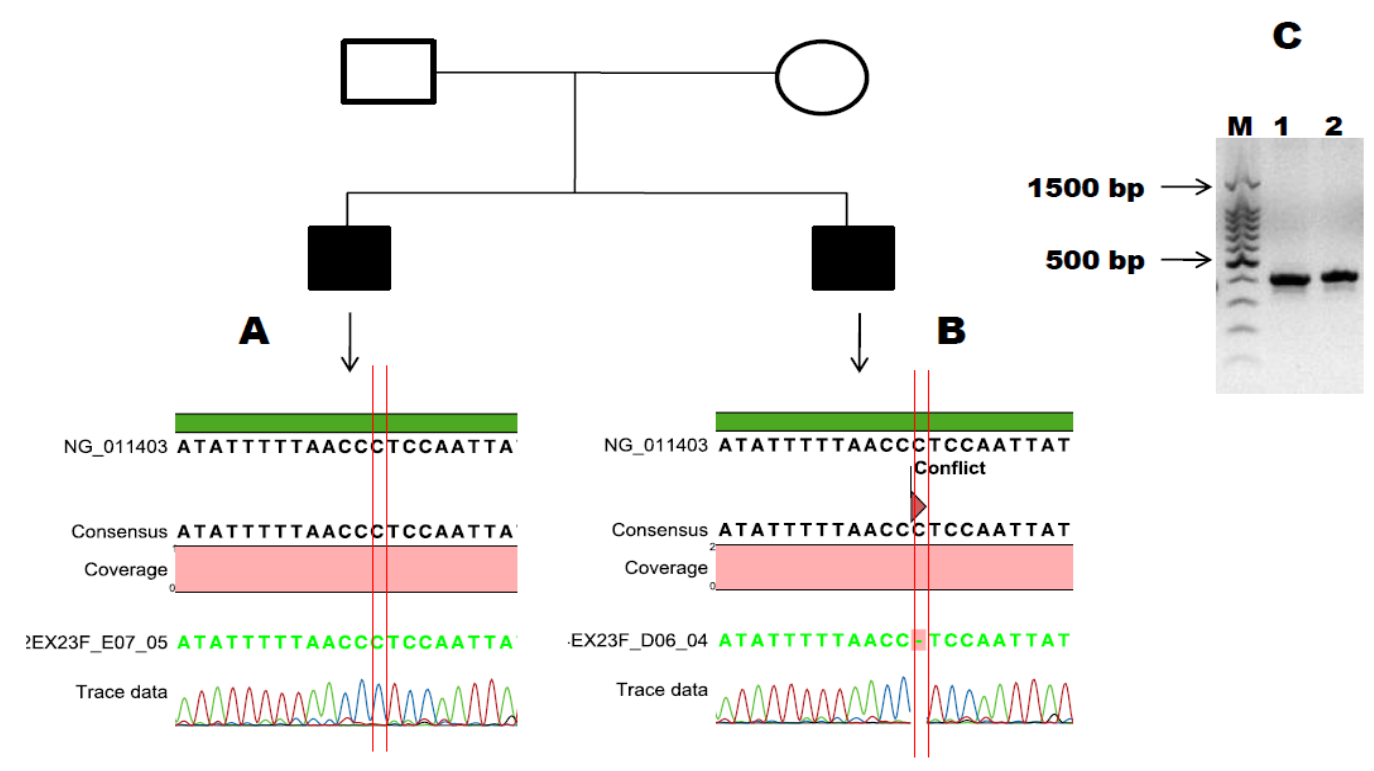

Figure 4: Identification of a novel frame shift mutation in factor VIII gene c.6482delC, p. (P2161 Lfs $\left.{ }^{\star} 25\right)$ causing hemophilia A. Family pedigree, open square and open circle represents parents (father and mother respectively), filled squares represents male family member. (A) Representative Electrophoregram showing WT genotype. B) Representative Electrophoregram showing WT genotype. ( B) Representative electrophoregram showing the mutation (conflict) in exon 23 of factor VIII gene. (C) PCR gel image of exon 23 of factor VIII showing single specific bands of product size, 416 bp in patient and WT (Lanes - 1, 2). M represents 100 bp ladder.

$<1 \%$ in this patient, with joint disability in right knee, this patient did not have any systemic manifestations. This patient was on prophylaxix treatment with plasma derived clotting factor concentrate.

In exon 4 a known mutation in 2 patients with ages of 51 yrs and 29 years respectively was found. This mutation c.409 A>C, p.(T137P); (ACC>CCC) is associated with severe form of haemophillia $(33,34)$. Both cases have factor VIII base line levels of $<1 \%$, and have chronic joint disabilities patient also had HIV and was a diabetic. A representative electrophoregram for one family is shown in Figure 5. In Figure 5 panel $\mathrm{A}$, is for the wild type control, and in panel $\mathrm{B}$, for the patient with mutation in exon 4 . In panel C, PCR gel picture is shown for exon 4, PCR product size is $388 \mathrm{bp}$, the acutal size of the exon 4 is 213 bp. In Figure 6, another known mutation is shown, this is a missense mutation in exon $12, \mathrm{c} .1804 \mathrm{C}>\mathrm{T}, \mathrm{p} .\left(\mathrm{R} 602^{*}\right)$. This patient was a 8 years old male Saudi with episodic bleeding, he has factor VIII levels of less than $1 \%$ and being treated with more than one product for hemophilia (Tables 3 and 4). This patient did not have joint pains, but 


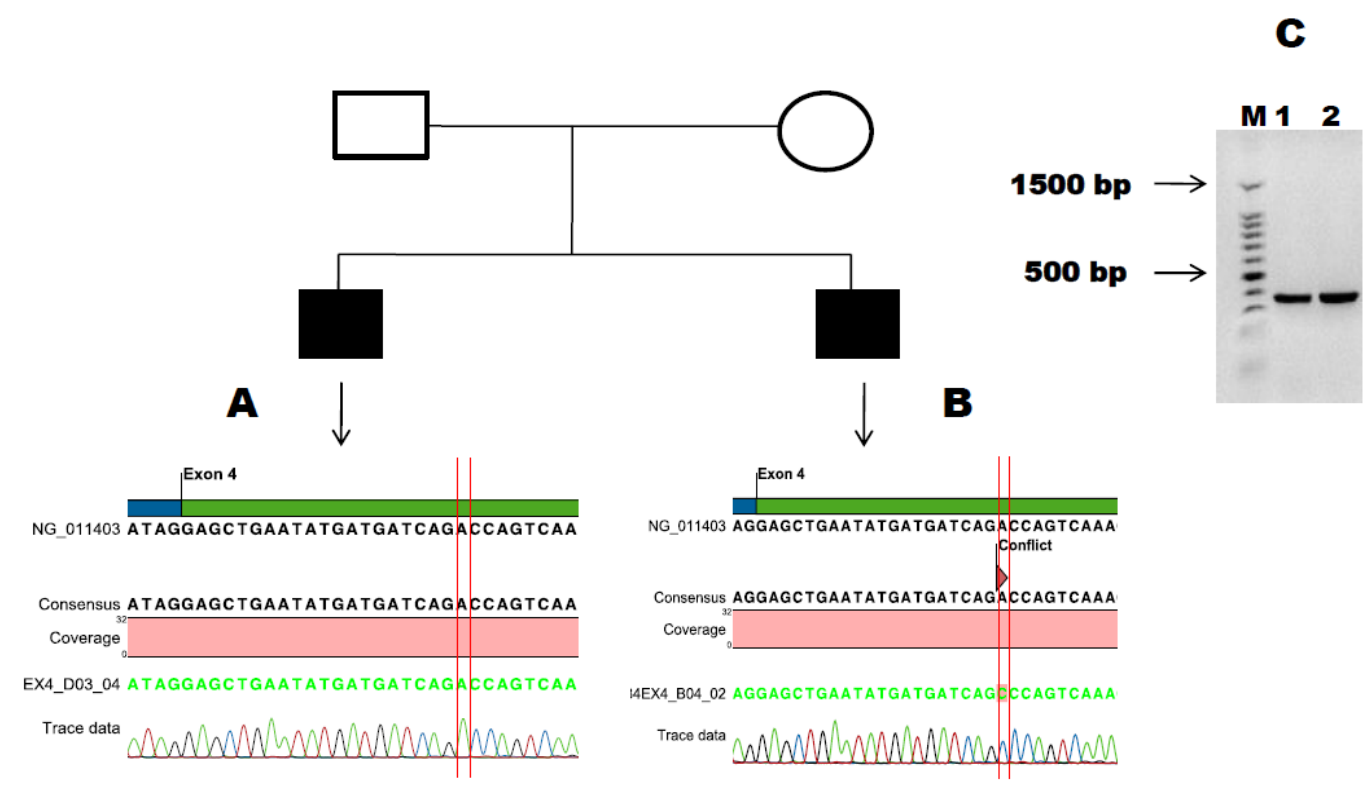

Figure 5: Identification of a known missense mutation in factor VIII gene c.409A $>C$, p.(T137P) causing hemophiliaA in Saudi Arabian patients. Family pedigree, open square and open circle represents parents (father and mother respectively), filled squares represents male family member. (A) Representative Electrophoregram showing WT genotype. (B) Representative Electrophoregram showing the mutation (conflict) in exon 4 of factor VIII gene. (C) PCR gel image of exon 4 in factor VIII showing single specific band of product size, 388bp in patient and WT (Lanes - 1, 2). M represents 100 bp ladder.

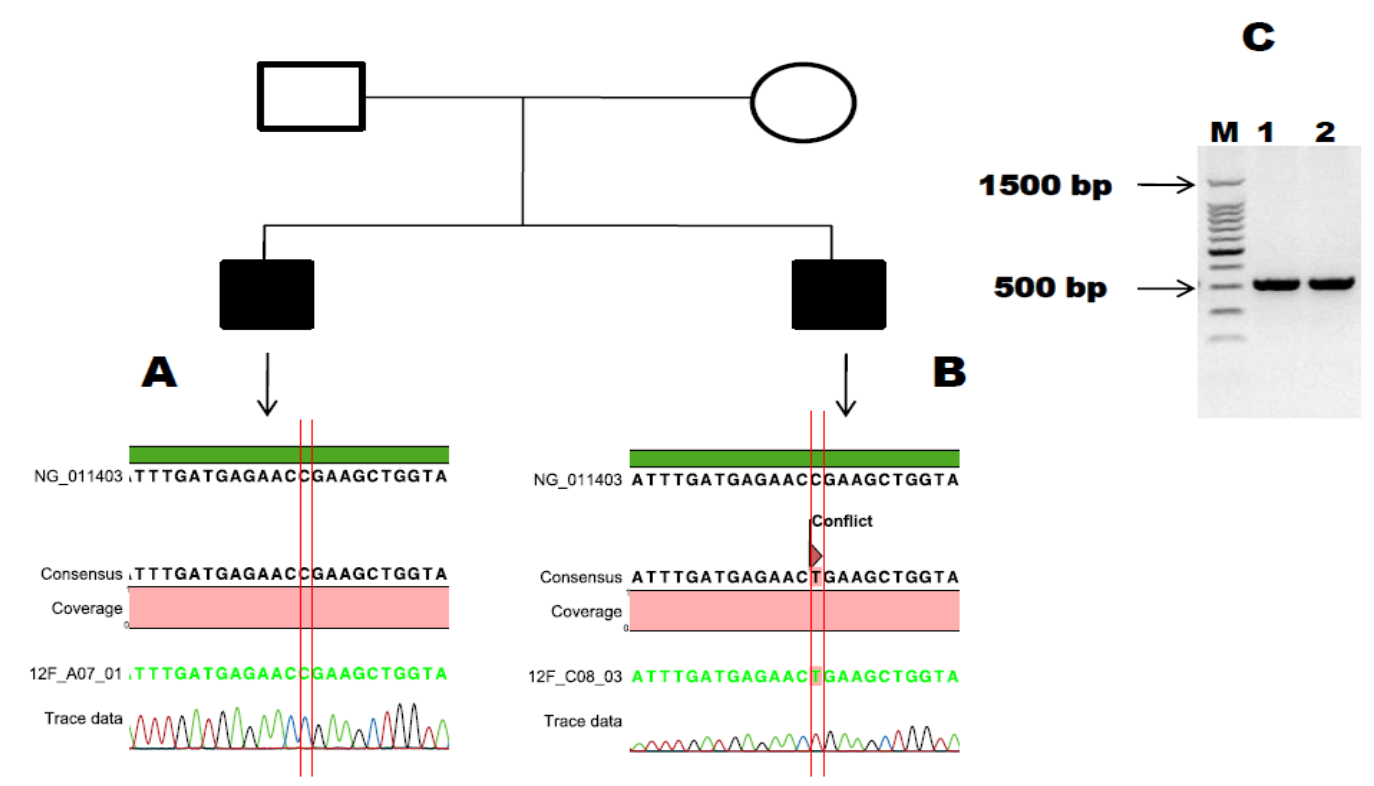

Figure 6: Identification of a known missense mutation in factor VIII gene c.1804C>T, p. (R602*) in Saudi Arabian patients. Family pedigree, open square and open circle represents parents (father and mother respectively), filled squares represents male family member. (A) Representative Electrophoregram showing WT genotype. (B) Representative Electrophoregram showing the mutation (conflict) in exon 12 of factor VIII gene. (C) PCR gel image of exon 12 of factor VIII showing single specific band of product size, $320 \mathrm{bp}$ in patient and WT (Lanes - 1, 2). The actual exon 12 size is $151 \mathrm{bp}$. M represents $100 \mathrm{bp}$ ladder.

had systemic manifestations such as recurrent urinary tract infections. This mutation in arginine codon (CGA $>$ TGA) makes a stop codon causing a truncated protein production. This mutation is reported to be associated with severe to moderate form of haemophillia. The electrophoregrams and the gel picture is shown below in Figure 6.

\section{Molecular dynamic simulation studies of missense mutation} in exon 3, [c.355G >C, p. (A119P)]

The annotation for the missense mutation within the gene on $\mathrm{X}$ chromosome was performed. This mutation provides information for the translated regions of the factor VIII gene in exon 3. Factor VIII gene coding regions of the protein structure retrieved from the Protein Data Bank (PDB) database, we resolved the structure from UniProtKB (P00451; FA8_HUMAN; PDB ID: 2R7E). This structure was typically from five domains (A1- A2-A3; C1-C2), and two chains A-B, but our targeted sequence aligned with only with the "Chain $A$ " within a domain A1 with regard to the structure assembly simulations (Figures 7A-7D). The factor VIII associated protein domain "Chain A" mutated 
Citation: Al-Allaf FA, Taher MM, Abduljaleel Z, Athar M, Ba-hammam FA, et al. (2016) Mutation Screening of the Factor VIII Gene in Hemophilia A in Saudi Arabia: Two Novel Mutations and Genotype-Phenotype Correlation. J Mol Genet Med 10: 211 doi:10.4172/1747-0862.1000211

Page 7 of 11

structure on was within Loop at Ala119Pro. The predicted factor VIII evaluation was determined using a Ramachandran plot with a favored region $(90.0 \%)$, an allowed area $(2.0 \%)$, and an outlier region $(11.4 \%)$. We found greater than $95 \%$ of the residues in the most favored regions, which showed that the quality of the structure was comparable to the template. The residues were scanned, and loop mutation analysis was performed for factor VIII gene. The consensus method was used on an additional critical residue with a hot residue to increase the thermodynamic stability of factor VIII, and this technique was simple in comparison to previously described strategies (Figures 7A-7D).

The energy minimization of factor VIII before the mutation was performed at -321 $951.904 \mathrm{~kJ} / \mathrm{mol}$, which decreased to $-297519.203 \mathrm{~kJ} /$ mol after mutation of Ala119 in factor VIII gene, these energy changes were calculated by using BioLuminate. The energy minimization was based on the set of selected polar and non-neutral residues for these screenings. We fixed the refinement cut of $0.00 \AA$ with an implicit solvent minimization. The result of decreasing the minimized energy value of the Loop: Ala119 Pro showed that the substitution of Ala to Pro119 may contribute to improved compactness and may increase protein folding. Further loop mutation was based on the implicit solvent according to $\mathrm{MD}$ simulations. Compared to the results at a temperature of $300 \mathrm{~K}$, the deviation of the factor VIII protein increased from $2.0 \AA$ to $10 \mathrm{~ns}$. In contrast, the deviation of mutation Ala119Pro was maintained at $1.2 \AA$ until the end of the simulation ( $\mathrm{t}=10 \mathrm{~ns})$, which showed that Ala119 Pro had reached its folded state. The small peak at 1.3ns indicated that Ala119 Pro stabilized the structure. Our results showed that the Ala119 Pro structure was stable and could maintain its conformation at $300 \mathrm{~K}$, at a pressure bar of 1.01225 with a surface tension 4,000.0 $\AA$, in a total simulation time (ns) of 1.2/elapsed 0.0, and recording interval (ps) energy of 1.2. However, there were subtle changes that were observed between wild type and mutated factor VIII (Loop: Ala119 Pro), as revealed by the superimposed structures with a RMSD value of $1.516 \AA$, which were determined using MOE. Ala119 of the factor VIII protein showed a higher solvent accessibility than Pro119 in the protein structure. In a further analysis of annotated predicted solvent accessibility and pre-calculated packing density, Ala119 Pro was found to increase the density and lessen the internal cavities compared to the wild type form. Thus, substitution of a residue (Ala119) with Pro119 enhanced the packing and compactness of the mutant structure.

\section{Molecular dynamic simulation studies of frame shift mutation in exon 23 [c.6482delc, p. $\left(\right.$ p2161lfs $\left.{ }^{\star} 25\right)$ ]}

The annotation for the frame shift mutation c.6482delC, p. $\left(\mathrm{P} 2161 \mathrm{Lfs}^{\star} 25\right)$ in exon 23 within the gene on $\mathrm{X}$ chromosome was performed. This structure, belonged to factor VIII gene coding regions of the protein structure retrieved from the Protein Data Bank (PDB) database, we resolved the structure from UniProtKB (P00451 (FA8 HUMAN), (PDB ID: 2R7E). This structure was typically from five

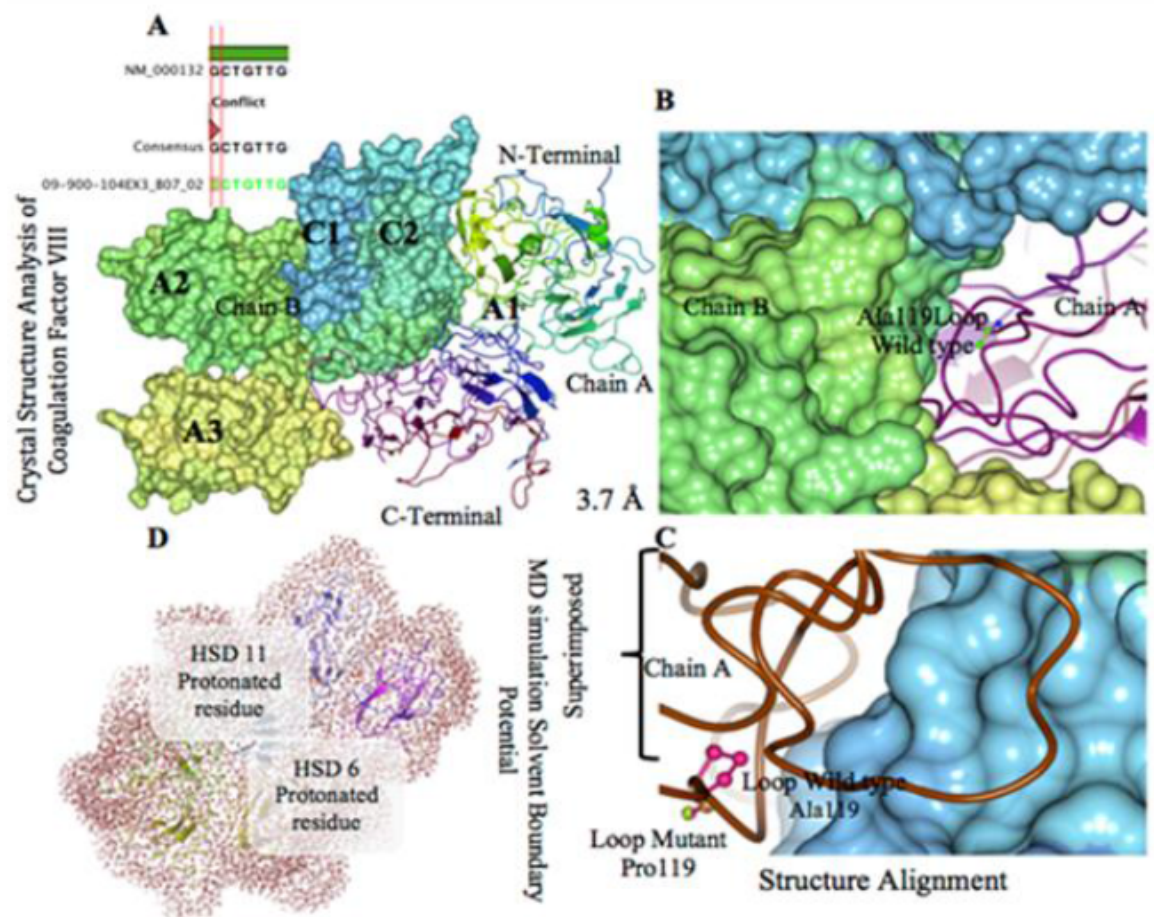

$0.51 \mathrm{M}$ ion $/ \mathrm{KCI}$ ion (Simulation)

Truncated Boundary explicit water solvated system

3,001 water molecules and solvate protein with edge distance $10 \mathrm{~A}$ cutoff

Figure 7: Crystal structure of Factor VIII domains and molecular dynamics (MD) simulation showing Ala119Pro mutation located in the interface the A1 domain. (A) Crystal structure of coagulation domains F8 (PDB ID 2R7E), the domains are individually labeled and in different colors. Indicate the positions of the mutations studied and sequence alignment with sample reads shown in the mutation $G>C$. B) Close-up views of the positions of the mutation with the mutated and nearby residues shown as ball and stick models as dashed circle. C) The Ala119Pro mutation located in the interface the A1 domain. A and Tertiary structure of the wild type chain A of factor VIII protein showing hemophilia disease causing mutations i.e. grey Ala119. Green Pro119, on loop region near with alpha helix10 modeling. D) The visual inspection also allow to identify the side chain of a histidine residue involved in the hydrogen bonding with surrounding molecules and in that case the $\delta$ nitrogen of the histidine (HSB) is protonated residue. The MD simulations system used in calculations are; water box surrounding the entire protein (middle). 
Citation: Al-Allaf FA, Taher MM, Abduljaleel Z, Athar M, Ba-hammam FA, et al. (2016) Mutation Screening of the Factor VIII Gene in Hemophilia A in Saudi Arabia: Two Novel Mutations and Genotype-Phenotype Correlation. J Mol Genet Med 10: 211 doi:10.4172/1747-0862.1000211

Page 8 of 11

domains (A1- A2-A3; C1-C2), but our targeted position not cover on these domains. We predict the truncated protein by homology method (Figures $8 \mathrm{~A}-8 \mathrm{C}$ ). The mutation for corresponding positions were viewed individually to examine the altered model structures achieved utilizing CCP4 (QtMG). The predicted factor VIII structure was evaluated using a Ramachandran plot with a favored region $(97.0 \%)$, an allowed area $(2.0 \%)$, and an outlier region $(10.4 \%)$. We found greater than $96 \%$ of the residues in the most favored regions, which showed that the quality of the structure was comparable to the template [48]. The residues c.6482delC, p. (P2161LFs $\left.{ }^{\star} 25\right)$ were scanned, and Helix mutation analysis was performed for factor VIII gene [49]. Mutation of p.(P2161LFs $\left.{ }^{\star} 25\right)$ in factor VIII and another thermo stable site were targeted as critical residues and were substituted using Schrodinger (BioLuminate). The energy minimization of factor VIII before the mutation was performed at $-521891.904 \mathrm{~kJ} / \mathrm{mol}$, which decreased to $-317569.201 \mathrm{~kJ} / \mathrm{mol}$ after mutation, as calculated by using BioLuminate. The energy minimization was based on the set of selected polar and non-neutral residues for these screenings. We fixed the refinement cut of $0.00 \AA$ with an implicit solvent minimization. The result of decreasing the minimized energy value of the Loop: p. (P2161LFs $\left.{ }^{\star} 25\right)$ showed that the frame shift may contribute to improved compactness and may increase protein folding. Compared to the results at a temperature of $300 \mathrm{~K}$, the deviation of the factor VIII protein increased from $2.0 \AA$ to $10 \mathrm{~ns}$. In contrast, the deviation of frame shift mutation c.6482delC, p. (P2161LFs $\left.{ }^{\star} 25\right)$ was maintained at $1.2 \AA$ until the end of the simulation $(t=10 \mathrm{~ns})$, which is reached its folded state.

\section{Discussion}

Hemophilia $\mathrm{A}$ is an inherited disorder of blood coagulation factor VIII, and haemophilic patients suffer from prolong bleeding time after trauma or injuries. The aim of this study was to investigate mutations in the factor-VIII gene in Saudi Arabian population. There are few previous reports about hemophilia A screening in the Middle Eastern population, specifically in Saudi Arabian Population by Owaidah, et al. in Lebanese population by Khayat, et al. in Tunisian population by Elmahmoudi, et al. [50] and in Jordanian population by Awidi, et al. [31]. In the present study mutational screenings of factor VIII gene sequencing analysis, and intronic rearrangements such as, inv-1 and inv-22 analysis were performed in the hemophilia A patients of Saudi Arabian population. The factor VIII mutation database includes more than 1000 unique mutations in hemophiliac patients [51]. We have sequenced 32 DNA samples of Saudi Arabian origin, and this study has identified two novel mutations that were not reported in either of these databases. Also, the mutation c.355G>C, p. (A119P) in exon 3 and another mutation c.6482delC, p.P2161Lfs ${ }^{\star} 25$ in exon 23 were not reported in any current literature search using the PubMed/Medline database to the best of our knowledge. These potentially deleterious mutations correlated well with the severity of phenotype. The molecular pathology of these novel mutations was studied by molecular modeling. Two previously reported mutations in exon 4 and exon 12 respectively, were also found in Saudi Arabian cases.
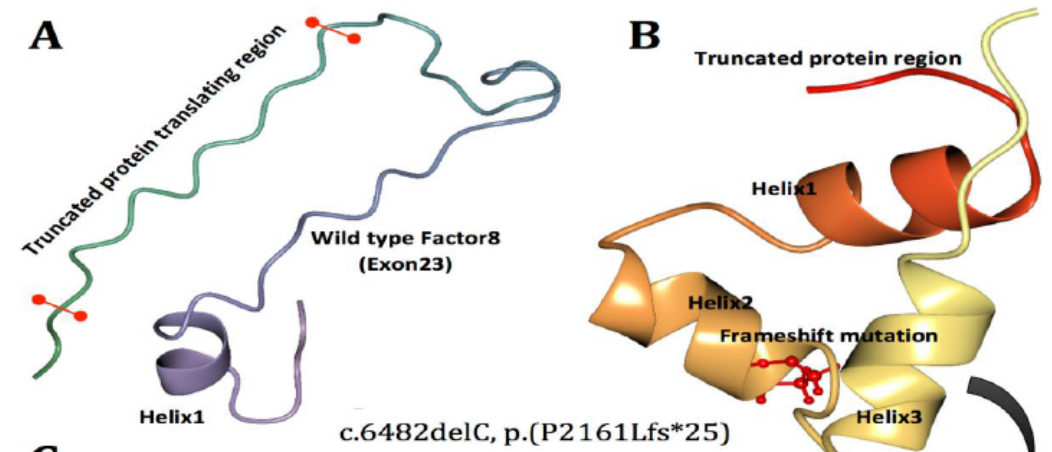

C

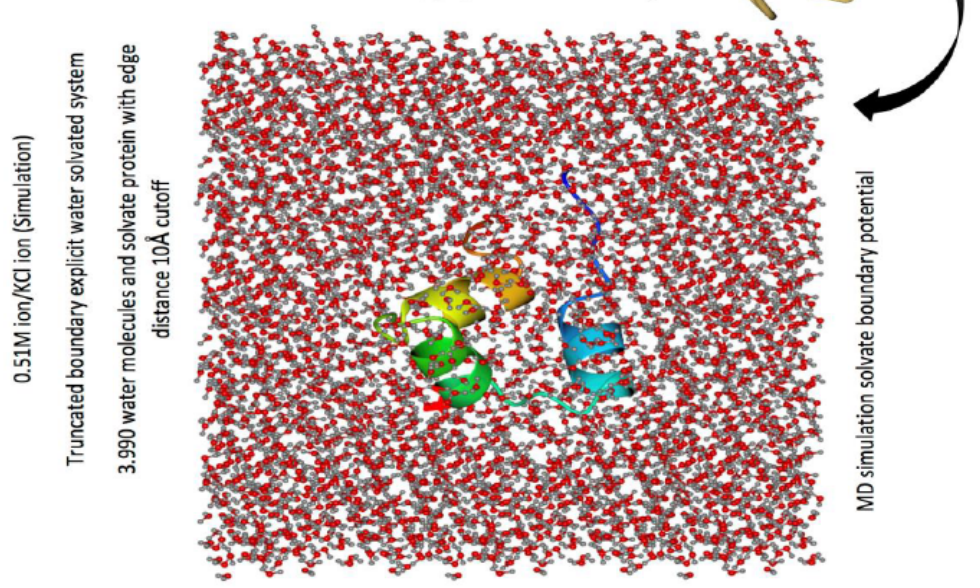

Figure 8: Molecular dynamics (MD) simulation showing the tertiary structure of truncated factor VIII protein for the factor VIII frame shift mutation p.(P2161LFs 25$)$ on the helix1, truncated boundary explicit water solvated and hydrogen atoms are in color. (A) Structural Model of coagulation domains of factor VIII gene. The domains are individually labeled and in different colors. B) Damaged truncated region structure views and the mutation shown as ball and stick models as dashed circle. Mutation c.6482delC, p. (P2161LFs $\left.{ }^{2} 25\right)$ located in the Helix2. The Tertiary structure of truncated factor VIII protein model showing hemophilia A frame shift mutation p.(P2161LFs*25) on the helix1. (C) The visual inspection allow to identify the side chain of a histidine residue involved in the hydrogen bonding with surrounding molecules and the $\delta$ nitrogen of the histidine (HSB) is protonated. The MD simulations system used in calculations are; water box surrounding the entire protein (middle). 
The hemophilia disease severity is predicted by type of mutation found in factor VIII gene. Mutations that cause severe disruption of factor VIII protein structure or alter an important functional site will result in disease severity. The prevalence of factor VIII inv-1 in Saudi Arabian population is not yet clearly understood. There were two previously reported studies by Abu-Amero, et al. and Owaidah, et al. on factor VIII mutation analysis; however they have not performed inv-1 analysis in that. Our report appears to be the first report of inv-1 detection in Saudi Arabian population. We have screened 110 patients for inv-1 by multiplex PCR method, and found a frequency of $1.8 \%$ of inv-1 positive in Saudi Arabian patients. Intron-1 inversion mutation is the second most common mutation in severe hemophilia $\mathrm{A}$ in the factor VIII gene. It was initially reported to be present in approximately $5 \%$ of patients [52] other studies reported around 2-3\% of hemophilia cases known to have intron-1 inversion. However, in the UK severe hemophilia A population it was subsequently found to have a frequency of $1.8 \%$ [53]. The data obtained in this study is agreement with these published reports.

In severe hemophilia A inv-22 is the most prevalent mutation in factor VIII gene. It is well known that the protocol such as, long-PCR for detection of inv-22 is not a straight forward procedure [52,54]. This kind of inversions is detected by Southern blotting, which is slow and labor-intensive. The prevalence of inv-22 in hemophilia A in different countries is quite variable with a range of $17.6 \%$ to $46.8 \%$ [55]. Keeney, et al. [56] have reported $20 \%$ positive with inv-22 in British population. In another study Oldenburg, et al. [57] reported that factor VIII intorn-22 rearrangements which accounts for $23 \%$. Diagnostic test of IS-PCR detected int22h-related rearrangements in $33.3 \%$ (23.3\% rearrangements and $10 \%$ of deletion 22 ) of hemophilia A in Egyptian patients (36). In previous studies where a $40-45 \%$ of inv-22 positive cases were reported used the long-PCR method. In the Turkish population, this inversion mutation accounts for $42 \%$ of severe cases [58]. There is no extensive study to describe the prevalence of inv-22 in Saudi patients. One report by Abu-Amero, et al. (34) used only six cases from Saudi Arabia in a total of 20 Arab patients for analysis on inv-22, and reported $45 \%$ are positive.

In the present study, we have used the inverse PCR method published by Rossetti, et al. (35). A new version of this method known as inverse-shifting PCR (IS-PCR) published by the same group [21] detects both proximal and distal inversions, and also insertions and deletions resulting from additional int-22h recombination events. This test involves four primers set (ID, IU, 2U, and $3 \mathrm{U}$ ) as described in Rossetti, et al [21]. However, we have used three primers set (ID, ED, and IU) as reported in inv-22 method of 2005 . This could be the reason for this discrepancy in frequencies. It is also reported that the results of IS-PCR match perfectly with the long-PCR results $[21,36]$. However, it remains to be investigated thoroughly all types of int-22h related rearrangements which includes inversions, deletions, and duplications in Saudi Arabian patients.

Our In-silico study suggests that the novel mutations we found have significant impact on the structure and function of the factor VIII protein. We have also studied the molecular structure by MD simulations by immersing them in a solvent using superior simulation parameters as well as energy minimization to analyze the simulation in terms of potential energies, structural fluctuations, coordinate stability and geometrical features. We have observed that the mutation in exon 3 was located within a domain, annotated in UniProt as: "F5/8 type A 1; Plastocyanin-like 1". The mutation introduces an amino acid with different properties, which can disturb this domain and abolish its function. The proline that is introduced by this mutation might abolish the required flexibility of the protein at this position. The mutation was located in a region with known splice variants, described as: "In isoform 2". The mutant residue was located near a highly conserved position, this residue was part of an interpro domain named "Cupredoxin" (IPR008972), and this was also buried in the core of a domain. The differences between the wild type and mutant residue might disturb the core structure of this domain.

In summary, our study has identified two novel mutation c.355G >C, p. (A119P) and c.6482delC, p.(P2161Lfs $\left.{ }^{\star} 25\right)$ in Saudi Arabian patients that were not reported previously in any factor VIII databases. Our results showed that this is a deleterious mutation in factor VIII gene and it is associated with pathological conditions and clinically significant as determined by Molecular Dynamics Simulation studies. These potentially deleterious mutations correlated well with the severity of phenotype of the patient. Pathogenic characteristics of this novel mutation was determined based on the standard criteria using PolyPhen database, and found to be deleterious in function, as this correlates with the patient's severity of hemophilia. The molecular pathology of these novel mutations were studied by Molecular Dynamics Simulation. We found a frequency of $1.8 \%$ of inv-1 positive in Saudi Arabian patients, and this is the first investigation of inv-1 in Saudi Arabian patients. Intron-1 and intron-22 inversions are the most common mutations in severe hemophilia A in factor VIII gene. However, there is no extensive study to describe the prevalence of these inversions in Saudi Arabian population. We have found 20\% were positive in severe cases ( 15 out of 75 ) for inv-22 in the factor VIII gene; this observation is in contrary to the published reports. We suggest that further studies are needed with large number of patients.

\section{Acknowledgement}

We are indebted to the pateints and their family members participated in this study. The authors would like to thank the staff of Science and Technology Unit at Umm Al-Qura University for the continuous support. This work was supported by the National Science, Technology, and Innovative Plan (MAARIFAH) of the Kingdom of Saudi Arabia to Dr. Faisal A. Al-Allaf, ( Grant Code: 09-BIO920-10).

\section{Authors Contribution}

FAA. Conceived the idea, designed the research and analyzed data. MMT, $M A, A B, M A$ and $Z A$. Performed experiments and analyzed data. FAA, TO, MMT and $Z A$. Wrote the paper. HA, FAB. and TO. Contributed to vital reagents.

\section{Details of Nature of Conflict of Interest}

All authors agreed with the contents of this manuscript and all authors declare no conflict of interest in publishing this manuscript.

\section{References}

1. White GC 2nd, Rosendaal F, Aledort LM, Lusher JM, Rothschild C, et al. (2001) Definitions in hemophilia: recommendation of the scientific subcommittee on facto VIII and factor IX of the scientific and standardization committee of the international society on Thrombosis and Haemostasis. Thromb Haemost 85: 560.

2. HAMSTeRs (2014) The Hemophilia A mutation, structure, test and resource site.

3. Klinge J, Ananyeva NM, Hauser CA, Saenko EL (2002) Hemophilia A-from basic science to clinical practice. Semin Thromb Hemost 28: 309-322.

4. Hoyer LW (1994) Hemophilia A. N Engl J Med 330: 38-47.

5. Lenting PJ, van Mourik JA, Mertens K (1998) The life cycle of coagulation factor VIII in view of its structure and function. Blood 92: 3983-3996.

6. Thompson AR (1986) Structure, function, and molecular defects of factor IX Blood 67: 765-772.

7. Anson DS, Choo KH, Rees DJG, Giannelli F, Gould K, et al. (1984) The gene structure of human anti-haemophilic factor IX. EMBO J 3: 1053-1060. 
Citation: Al-Allaf FA, Taher MM, Abduljaleel Z, Athar M, Ba-hammam FA, et al. (2016) Mutation Screening of the Factor VIII Gene in Hemophilia A in Saudi Arabia: Two Novel Mutations and Genotype-Phenotype Correlation. J Mol Genet Med 10: 211 doi:10.4172/1747-0862.1000211

Page 10 of 11

8. Yoshitake S, Schach BG, Foster DC, Davie EW, Kurachi K (1985) Complete nucleotide sequences of the gene for human factor IX (antihemophilic factor B). Biochemistry 24: 3736-3750.

9. Forbes CD (1997) The early history of hemophilia. Chapman \& Hall, London.

10. Bolton-Maggs PH, Pasi KJ (2003) Hemophilias A and B. Lancet 361: 18011809.

11. Asakai R, Chung DW, Davie EW, Seligsohn U (1991) Factor XI deficiency in Ashkenazi Jews in Israel. N Engl J Med 325: 153-158.

12. Hancock JF, Wieland K, Pugh RE, Martinowitz U, Schulman S, et al. (1991) A molecular genetics study of factor XI deficiency. Blood 77: 1942-1948.

13. http://www.moh.gov.sa/en/HealthAwareness/EducationalContent/Diseases/ Hematology/Pages/006.aspx.

14. Gitschier J, Wood WI, Goralka TM, Wion KL, Chen EY, et al. (1984) Characterization of the human factor VIII gene. Nature 312: 326-330.

15. Goodeve AC, Peake IR (2003) The molecular basis of hemophilia A: genotypephenotype relationships and inhibitor development. Semin Thromb Hemost 29: 23-30.

16. Boekhorst J, Verbruggen B, Lavergne JM, Costa JM, Schoormans SC, et al. (2005) Thirteen novel mutations in the factor VIII gene in the Nijmegen hemophilia A patient population. Br J Haematol 131: 109-117

17. Repessé Y, Slaoui M, Ferrandiz D, Gautier P, Costa C, et al. (2007) Factor VIII (FVIII) gene mutations in 120 patients with hemophilia A: detection of 26 nove mutations and correlation with FVIII inhibitor development. J Thromb Haemost 5: 1469-1476.

18. Nielsen LR, Scheibel E, Ingerslev J, Schwartz M (1995) Detection of ten new mutations by screening the gene encoding factor IX of Danish hemophilia B patients. Thromb Haemost 73: 774-778.

19. Graw J, Brackmann HH, Oldenburg J, Schneppenheim R, Spannagl M, et al (2005) Hemophilia A: from mutation analysis to new therapies. Nature Rev Genet 6: 488-501.

20. Casaña P, Mayo S, Monfort S, Orellana C, Haya S, et al. (2012) Large deletion in the Factor VIII gene (F8) involving segmental duplications in int22h shows no haematological phenotype in female carriers, but may be embryonic lethal in males. $\mathrm{Br} \mathrm{J}$ of Haematol 158: 138-140.

21. Rossetti LC, Radic CP, Larripa IB, De Brasi CD (2008) Developing a new generation of tests for genotyping hemophilia-causative rearrangements involving int22h and int $1 \mathrm{~h}$ hotspots in the factor VIII gene. J Thromb Haemos 6: $830-836$.

22. Liu Q, Sommer SS (1998) Subcycling-PCR for multiplex long-distance amplification of regions with high and low GC content: application to the inversion hotspot in the factor VIII gene. BioTechniques 25: 1022-1028.

23. Liu Q, Nozari G, Sommer SS (1998) Single-tube polymerase chain reaction for rapid diagnosis of the inversion hotspot of mutation in hemophilia A. Blood 92: $1458-1459$.

24. Bagnall RD, Waseem N, Green PM, Giannelli F, et al. (2002) Recurren inversion breaking intron 1 of the factor $\mathrm{VIII}$ gene is a frequent cause of severe hemophilia A. Blood 99: 168-174.

25. Jayandharan G, Shaji RV, Baidya S, Nair SC, Chandy M, et al. (2005) Identification of factor VIII gene mutations in 101 patients with Hemophilia A mutation analysis by inversion screening and multiplex PCR and CSGE and molecular modelling of 10 novel missense substitutions. Haemophilia 11: 481 491.

26. Antonarakis SE, Rossiter JP, Young M, Horst J, de Moerloose P, et al. (1995) Factor VIII gene inversions in severe hemophilia A-results of an international consortium study. Blood 86: 2206-2212.

27. Miller CH, Hilgartner MW, Aledort LM (1987) Reproductive choices in hemophilic men and carriers. Am J Med Genet 26: 591-598.

28. Kasper CK, Lin JC (2007) Prevalence of sporadic and familial hemophilia Haemophilia 13: 90-92.

29. Hwang SH, Kim MJ, Lim JA, Kim HC, Kim HS (2009) Profiling of factor VIII mutations in Korean hemophilia A. Haemophilia 15: 1311-1317.

30. Citron M, Godmilow L, Ganguly T, Ganguly A (2002) High throughput mutation screening of the factor VIII gene (F8C) in hemophilia A: 37 Novel mutations and genotype - phenotype correlation. Hum Mutat 20: 267-274.

31. Awidi A, Ramahi M, Alhattab D, Mefleh R, Dweiri M (2010) Study of mutations in Jordanian patients with hemophilia A: identification of five novel mutations. Hemophilia 16: 136-142.

32. Djambas Khayat C, Salem N, Chouery E, Corbani S, Moix I, et al.(2008) Molecular analysis of F8 in Lebanese hemophilia A patients: novel mutations and phenotype-genotype correlation. Haemophilia 14: 709-716.

33. Owaidah TM, Alkhail HA, Zahrani HA, Musa AA, Saleh MA, et al. (2009) Molecular genotyping of hemophilia $A$ in Saudi Arabia: report of 2 novel mutations. Blood Coagul Fibrinolysis 20: 415-418.

34. Abu-Amero KK, Hellani A, Al-Mahed M, Al-Sheikh I (2008) Spectrum of factor VIII mutations in Arab patients with severe hemophilia A. Hemophilia 14: 484 488.

35. Polakova H, Zmetakova I, Kadasi L (2003) Long distance PCR in detection of inversion mutations of $\mathrm{F} 8 \mathrm{C}$ gene in hemophilia A patients. Gen Physiol Biophys 22: 243-253.

36. Rossetti LC, Radic CP, Larripa IB, De Brasi CD (2005) Genotyping the hemophilia inversion hotspot by use of inverse PCR. Clin Chem 51: 1154-1158.

37. Abou-Elew H, Ahmed H, Raslan H, Abdelwahab M, Hammoud R, et al. (2011) Genotyping of intron 22-related rearrangements of F8 by inverse-shifting PCR in Egyptian hemophilia A patients. Ann Hematol 90: 579-584.

38. Vidal F, Farssac E, Altisent C, Puig L, Gallardo D (2001) Rapid hemophilia A molecular diagnosis by a simple DNA sequencing procedure: identification of 14 novel mutations. Thromb Haemost 85: 580-583.

39. Viel KR, Machiah DK, Warren DM, Khachidze M, Buil A, et al. (2007) A sequence variation scan of the coagulation factor VIII (FVIII) structural gene and associations with plasma FVIII activity levels. Blood 109: 3713-3724.

40. den Dunnen JT, Antonarakis SE (2000) Mutation nomenclature extensions and suggestions to describe complex mutations: A discussion. Hum Mutat 15: 7-12.

41. Rodrigues JP, Levitt M, Chopra G (2012) KoBaMIN: a knowledge-based minimization web server for protein structure refinement. Nucleic Acids Res 40: W323-W328.

42. Delarue M, Dumas $P$ (2004) On the use of low-frequency normal modes to enforce collective movements in refining macromolecular structural models. Proc Natal Acad Sci USA 101: 6957-6962.

43. Darden T, Perera L, Li L, Pedersen L (1999) New tricks for modelers from the crystallography toolkit: the particle mesh Ewald algorithm and its use in nucleic acid simulations. Structure 7: R55-R60.

44. Venselaar H, Te Beek TA, Kuipers RK, Hekkelman ML, Vriend G (2010) Protein structure analysis of mutations causing inheritable diseases. An e-Science approach with life scientist friendly interfaces. BMC Bioinformatics 11: p548.

45. Prlic A, Down TA, Kulesha E, Finn RD, Kahari A, et al. (2007) Integrating sequence and structural biology with DAS. BMC bioinformatics 8: p333.

46. Bromberg Y, Rost B (2007) SNAP: predict effect of non-synonymous polymorphisms on function. Nucleic Acids Res 35: 3823-3835.

47. Bromberg Y, Overton J, Vaisse C, Leibel RL, Rost B (2009) In silico mutagenesis: a case study of the melanocortin 4 receptor. FASEB J 23: 3059 3069.

48. Ramachandran GN, Ramakrishnan C, Sasisekharan V (1963) Stereochemistry of polypeptide chain configurations. J Mol Biol 7: 95-99.

49. Vieille C, Zeikus GJ (2001) Hyperthermophilic enzymes: sources, uses, and molecular mechanisms for thermostability. Microbiol Mol Biol Rev 65: 1-43.

50. Elmahmoudi H, Khodjet-el-khil H, Wigren E, Jlizi A, Zahra K, et al. (2012) First report of molecular diagnosis of Tunisian hemophiliacs A: identification of 8 novel causative mutations. Diagn Pathol 7: 93

51. Higuchi M, Kazazian Jr HH, Kasch L, Warren TC, McGinniss MJ, et al. (1991) Molecular characterization of severe hemophilia A suggests that about half the mutations are not within the coding regions and splice junctions of the factor VIII gene. Proc Natal Acad Sci USA 88: 7405-7409.

52. Bagnall RD, Giannelli F, Green PM (2006) Int-22h-related inversions causing hemophilia A: a novel insight into their origin and a new more discriminant PCR test for their detection. J Thromb Haemost 4: 591-598.

53. Cumming AM (2004) The factor VIII intron 1 inversion mutation: prevalence in 
Citation: Al-Allaf FA, Taher MM, Abduljaleel Z, Athar M, Ba-hammam FA, et al. (2016) Mutation Screening of the Factor VIII Gene in Hemophilia A in Saudi Arabia: Two Novel Mutations and Genotype-Phenotype Correlation. J Mol Genet Med 10: 211 doi:10.4172/1747-0862.1000211

the UK. UK Haemophilia Centre Doctors' Organization. J Thromb Haemost 8 : 205-206

54. Bowen DJ, Keeney S (2003) Unleashing the long-distance PCR for detection of the intron 22 inversion of the factor VIII gene in severe hemophilia A. Thromb Haemost 89: 201-202.

55. Chen YC, Hu SH, Cheng SN, Chao TY (2010) Genetic analysis of hemophilia A in Taiwan. Hemophilia 16: 538-544.

56. Keeney S, Mitchell M, Goodeve A, (2005) UK Haemophilia Center Doctors'
Organization Haemophilia Genetics Laboratory Network. The molecular analysis of haemophilia A: a guideline from the UK Haemophilia Centre Doctors' Organization, Haemophilia Genetics Laboratory Network. Haemophilia 11 387-397.

57. Oldenburg J, Ananyeva NM, Saenko EL (2004) Molecular basis of hemophilia A. Haemophilia 10: 133-139.

58. El-Maarri O, Kavakli K, Caglayan SH (1999) Intron 22 inversions in the Turkish hemophilia A patients: prevalence and haplotype analysis. Hemophilia 5: 169-173. 